Philosophy and Progress: Vols. LIII-LIV, January-June, July-December, 2013 ISSN 1607-2278 (Print), DOI : http://dx.doi.org/10.3329/pp.v53i1-2.21949

\section{DILEMMATA AND DIMENSIONS OF CHILDREN'S READING COMPREHENSION SKILLS}

\author{
Mohammed Shamsul Hoque*
}

\begin{abstract}
Learners have to deal with texts they read in many different ways. Some learners comprehend better than others; some take a little while to get to the deeper meanings of the text while some get to the meaning instantly. Some may find it difficult to comprehend even at surface level. Psychologists, linguists and educators have been divided in their opinions about how a young learner comprehends a text and why they are better or worse than their peers in comprehending text. In this article attempts have been made to present a clear definition of what is comprehension; how comprehension happens among readers before, during and after reading; what makes a learner a good or a poor comprehender. While presenting this phenomenon in brief, mentions and citations have been made from established researches /studies in this area along with observations of acknowledged psycholinguists, educators and practitioners. Finally, with support from different studies, an attempt
\end{abstract}

\footnotetext{
* Assistant Professor in English, Daffodil International University, Dhaka Email : hoque.eng@daffodilvarsity.edu.bd
}

has been made to describe ways and means as to how to improve learners' reading comprehension.

\section{Keywords}

poor comprehender, good comprehender, reading proficiency, standardized reading, graphic knowledge, dyslexia, hyperlexia, garden variety of reading difficulty, constructive process, working memory, domain knowledge, visual imagery training.

\section{Introduction}

Academic success requires a learner to be a competent comprehender (Snowling, 2010). But readers can be poor comprehenders in the face of lack of sufficient basic reading skills. Poor comprehenders have difficulty constructing meaning of the text in they read. In a recent international comparison of children's reading achievement, the US fourthgraders ranked right in the middle of the international average. Their reading scores remained low in spite of dramatic increase in education expenditure nationally Jhingran (2011) in a study on primary-aged children of Bangladesh, Nepal, India and Sri Lanka reports that most of the pupils in all the countries except Sri Lanka in South Asia fail to read simple sentences meant for level 2 of expectation. This picture of children's reading difficulties may be a universal phenomenon not only in the countries where English is a second or a foreign language but also in the countries where English is the mother-tongue for almost all the children. So, numerous interventions have been designed in many countries to aid students' reading development. Derksen , 2012, refers to Cain \& Oakhill, 2006; Nation, Clark \& Snowling, 2002; Stothard and Hulme, 1995; and writes,

"Most interventions usually focus on teaching poor readers skills that good readers use. However, studies have shown that strategies of poor and good readers differ, which means 
that the interventions might teach poor readers skills which do not match the strategy they use. Moreover, various skills make up a good reader and it is unlikely poor readers lack all of these skills (p.10).”

Hence, there has always been a dilemma around the strategies of teaching poor readers strategies good readers use. It has been difficult to prove any one strategy or any particular set of strategies would be the most effective way to intervene. Studies including Stothard \& Hulme, 1995; Nation, Calrk, \& Snowling, 2002; Cain, Oakhill, \& Bryant, 2004; Cain \& Oakhill, 2006; and Derksen, 2012; concluded that poor comprehenders also find it difficult to read sentences using past forms of irregular verbs. None of the previous studies found any single cause for the reading difficulties of the poor comprehenders. Hence, the dilemma and so many dimensions of children's reading comprehension skills.

\section{1.i. What is reading comprehension?}

A simple definition of reading comprehension is to understand a written text which is read. But it is complex process. The process involves "constructing meaning" of a written material. It is considered to be thinking done before, during and after reading (Fountas, I.C., 2001, p.323). It is a process of interaction between the text and the reader's prior knowledge and experience and their immediate expectations. This interaction generates meaning which completes the process of comprehension. (Anderson, R.C., and Pearson, P.D., 1984). Kate Nation and Philip Angell (2006) write,

"To understand text, words need to be recognized and their meanings accessed, relevant background knowledge needs to be activated and inferences must be generated as information is integrated during the course of reading. In addition, control processes are needed to monitor both ongoing comprehension and the internal consistency of text, allowing the reader to initiate repair strategies (for example, rereading) if comprehension break down is detected."

The NLS (National Literacy Strategy), 1988, in the UK introduced a model called "searchlights model" shows what the reading process involves.

This model presents four strategies called "searchlights" that are used by the readers in reading a text (DfES,1988) The "searchlights" for readers to use in their reading, according to this model, are (a) Phonic sound and spelling, (b) word recognition and graphic knowledge, (c) grammatical knowledge and (d) knowledge of context. The 'gifted' or more able readers ( good comprehenders) use as many of these "searchlights" as possible; the less able readers (poor comprehenders) have a possibility of depending on less than four or a single of those "searchlights." Most psychologists including Fountas and Pinnel (2001) believe that students need to perform various tasks like use of prior knowledge and experience, thinking, inferencing, questioning and analyzing etc. There may be other factors affecting reading comprehension, e.g., context, motivation, levels and relevance of the text etc. Hence factors affecting comprehension can be many and diverse depending on the reader's age, background, ability, environment, motivation etc.

\section{1. ii. Components of reading comprehension}

Gough and Tunmer (1986) proposes a simple model of reading, which is $\mathrm{R}=\mathrm{DxC}$, where each variable ranges from 0 (nullity) to 1 (perfection) (p-6). There are many levels of comprehension which determines reader's ability to comprehend from a very low scale to a very high. They consider reading comprehension as 'linguistic' comprehension, a process by which word level information, sentences and discourses are interpreted. So, reading is an umbrella 
conception; decoding and comprehension are the two necessary components. Comprehension as a concept has its own components to be complete as a complex process. In this many readers excel naturally, many do well through hard work and appropriate intervention but some fail due to some form of reading disability. The most frequently discussed reading disabilities are: dyslexia, hyperlexia and garden variety reading disability. Dyslexia is an inability to decode; hyperlexia is an inability to comprehend and garden variety is an inability to decode and comprehend. Gough and Tunmer (1986) conclude that in the process of comprehension a reader not only uses decoding skills but also employs a host of other linguistic factors like knowledge of vocabulary, environment, visual and sensory images, processing and retaining information, skills of deduction etc. Graesser, Swamer, Bagget and Sell (1996) suggest that Knowledge, Pragmatics, Inferencing, Lexical processes, Memory etc. are the main components of comprehension. However, comprehension enables pupils to construct meaning from text through:

- $\quad$ activating background knowledge;

- monitoring own understanding of text;

- $\quad$ identifying what they do not understand and using appropriate strategy to synthesize, creating visual and other sensory imagery from text during and after reading;

- $\quad$ interpreting unknown vocabulary;

- generating question;

- $\quad$ re-telling text orally and in writing. Pupils are able to examine and extend meaning through:(a) making responding to text orally and in writing; (b) inference; (c) comparing complex concept of text;

\section{Pupils are also able to examine and extend meaning through:}

- making responses to text orally and in writing;

- inference;

- comparing complex concept of text;

- analyzing the text structure and story element.

\section{1.iii. Mental Models Theory and Inference}

Mental Models Theory (Johnson-Laird, 1983) reinforced by Gough and Tunmer (1986), Perfetti et al (1996) explains that comprehension is integrative in that the sentences in a text need to be integrated. The lexical and syntactic meaning of a text combined with background i.e. real world knowledge makes the process of comprehension successful. This model emphasises the integrative elements of comprehension which calls for a "constructive process" in which understanding is assisted by combining the text with real world knowledge. The role of this "real world knowledge" is vital in that this leads to an important component of comprehension, which is inference, the process of going "beyond the information given". Perfetti et al (1996) suggest that the reader uses his/her first understanding of the text and interpret this to retrieve the hidden or implied meaning of the text. This hidden meaning is the text base arguments and propositions that were not explicitly mentioned in the passage.(Singer and Ferreira, 1983). The process of inference brings out those understatements and implicit knowledge to the fore of understanding the text. This is nothing but the information that is activated during reading yet not explicitly stated in the text (Singer, 1994). Inference is a mental process which leads reader from known to the unknown. Perfetti et al (1996) writes: 
"What the reader tries to do, of course, is to make some connection between the words of the text and some piece of knowledge he or she has about the world. In making these connections, the reader builds a mental model ..."

Kintsch \& Van Dijk(1978), suggests a "situation model" which prescribes (text base+situation model=meaning comprehension is a lifelike mental representation of the people, setting etc. that are explicitly mentioned or inferentially suggested. Singer and Ferreira (1983) explain that inference is "text base arguments and propositions that were not explicitly mentioned in the passage." Singer (1994) reiterates that inference is "information that is activated during reading." This group of experts advocating for Mental Model Theory suggest two types of inference:

\section{- Implicit inference and}

\section{- Explicit inference.}

a) Implicit Inference is essential to make referential links in understanding the text. It has to be activated during the comprehension process. It is generated automatically and a prior knowledge is use long with context. Anaphoric reference as in the example,

\section{1. "The cup was in front of the fork.}

\section{2. "It was full of milk." and}

\section{3. "The cup was in front of the forks."}

"It was full of milk." can be shifted to different "anaphor", in this case, "The cup" and "The fork" referred to by pronoun "It". Because of the qualifier, "It", being a singular number, the reader of the text in question would automatically refer to the singular anaphora, "The cup" in the first text and the singular "The fork", not the plural "The forks" in the second text. But real life knowledge also comes into play. Forks cannot be full of milk. So the anaphoric reference will be assumed to be "The cup."

b) Explicit inference is necessitated after comprehension is completed. It involves a search for alternative conclusions. It involves the use of higher order skills to search for alternative models, or to change the current text representation. This could be deductive inference which is $100 \%$ certain and do not require the use of prior knowledge, or inductive reference which uses the background knowledge and draws a likely conclusion when all premises are not explicitly stated. "The girl entered the classroom with five apples in one hand and five in the other." In this text the inference, "five apples in the other" meaning "other hand" becomes obvious only when s/he deduces that because it refers to the obvious anaphora "apples", it must be "five apples in the other (meaning ' other hand'). This inductive inference uses the background knowledge and draws a likely conclusion of the 2 hidden meaning" in the text.

Oakhill (1982) writes, “Young children's reading comprehension skill is associated with their ability to draw inference.” Center, Y.; Freeman, L; Robertson, G.; and Outhred, L. (1999) write:

"Working with students of average ability at the word level, but with poor reading comprehension, Oakhill (Oakhill and Patel, 1991) 14found that such students do not appear to make inference from passage, nor do they integrate ideas from different sections of a text to form a coherent representation in the same way as do skilled comprehender (p-.242).”

\section{2. $i$. Why one is considered good or poor comprehender:}

Young learners have to be taught how to read. The curriculum right from the foundation level prescribes the contents along with methods and techniques of teaching reading. Yet 
considerable portion of school-going children miss out a lot of learning in other areas of the curriculum because of their poor reading skills.

A lot of children find it hard to master basic reading skills, e.g., word recognition, phonological awareness, in spite of their having average intelligence and ample opportunities to read. Tumner, Chapman, Greaney \& Prochnow,(2002); opine that children need to develop phonological awareness of the sounds of the words that they read and an ability to associate sounds appropriately in words are an important factor in the development of comprehension skills. However, MansetWilliamson and Nelson, ( 2005), report that a good lot of pupils are put into upper primary with significant deficiency in their reading skills.

There are concerns that these children ultimately reach a phase of their early learning life when it becomes difficult to teach them reading (Manset-Williams and Nelson, 2005). Kate Cain and Jane V. Oakhill (1999) conclude that skilled readers are able to construct integrated and coherent. They do it through their skills of making inference and, hence, they excel in comprehension better than their peers.

2.ii. According to Center et al (1999), failure to remember and understand connected text is a "salient feature' of a poor comprehender. They conclude that poor comprehenders face three main difficulties: they find it difficult to make inference; they fail to integrate ideas from the text that they read; and they do not carry on comprehension monitoring and have less welldeveloped story structure. This might happen to skilled 'decoders' as well. Yuill and Oakhill (1988) write:

"A competing account of poor comprehension is the 'decoding bottleneck' hypothesis suggested by Perfetti (1977). According to this view, children may show apparently adequate skills in word recognition and reading accuracy, but do not recognize words quickly and automatically. This show word recognition places an extra burden on the working memory, and therefore reduces resources available for comprehension." (p-35).

Virtually, everything that logically identified as a component of comprehension has been identified as a source of comprehension failure (Perfetti, C.A., et al. 1996, p-40). But some components of comprehension are more likely as sources of poor reading comprehension than others.

The central claim of Perfetti's " Verbal efficiency theory" is "certain processes were good candidates for becoming relatively resource free and that a failure to have such processes becomes resource free was a substantial cause of reading comprehension difficulties (Perfetti et al, 1996, p140)", The theory identified two particular sources of comprehension failure:

2.ii. (a): Working memory limitations: Working memory limitations put a reader in a jumbled up situation where organising information in a text in an orderly manner becomes difficult. Good comprehenders are able to use their working memory more actively than poor comprehenders. This hypothesis has been confirmed by many other studies including Carpenter and Just, 1988; Yuill, Oakhill and Parkin, 1989.

\section{2.ii.(b): Lexical processing difficulties}

Lexical processing difficulty also puts a reader in an unhelpful situation of organizing meaning and information in a text because " The lexical processing difficulties include sub-lexical processing, such as, knowledge of orthographic structure, phonological mappings to orthography, and so forth." ( Perfetti, Marron and Foltzel, p-140)," These two components are, according to most of the studies, the most inevitable sources of 
comprehension difficulties. There are other possible causes of comprehension difficulties, which, Perfetti and others consider theoretically coherent. These are:

2.ii.(c) Inference making: Comprehending a text demands the mental process of inferencing from a reader because "texts, even single sentences, cannot be fully explicit" (Perfetti et al, p-141).A reader must draw on other sources including many varieties of inference to fully comprehend a text.

\section{2.ii.(d) Comprehension monitoring}

It is an important process which a reader activates to assess if s/he understands a text.. It is a kind of building a systematic body of knowledge and information to construct the meaning of the text coherently.

\section{2.ii.(e) Word meaning}

Perfetti et al, 1996, conclude that a failure to understand words in a text can cause problems to comprehending the text. Readers can infer word meanings but it also may have limit at times. Anderson and Pearson, 1984 and Bos and Anders 1990, conclude that poor readers have difficulty with much of the vocabulary used to communicate academic concepts. Comprehension depends not only on the readers' general background knowledge regarding the topic at hand, but also on their familiarity with the specialized vocabulary used in the text. Poor comprehenders bring less of this knowledge to the reading task than the good comprehenders.

\section{2. ii(f): Domain knowledge}

Specialized subjects like psychology, or physics, require knowledge and vocabulary of this domain. So, understanding any specialized area of study requires understanding specialized concepts of that particular subject. Strategies like inference or monitoring comprehension may fail in understanding of subject-specific texts if it is not supported by domain knowledge. Perfetti et al, 1996, writes,

"The domain knowledge is a critical ingredient in the construction of a situation model. It links the reader's superficial, linguistically based representation of the text to a richer inference- based representation of the situation (p142)."

The first four components of comprehension failure have been grouped together as "processes"; and the last two as "knowledge."

\section{3.i. Differences between a good comprehender and a poor comprehender}

3.i.(a) Good comprehenders are strategic. They have sufficient reading and learning experiences. Many believe teaching one comprehension strategy helps a lot in improving comprehension. Many including National Reading Panel, 2004; NRP, 2001; Pressley, M., 2002; Wood and Enders, 2005 believe that Teaching multiple strategies can have larger impact and opines that good comprehenders use strategic processes and they develop meta-cognitic and self- explanatory processes. They are able to clarify, self-question and monitor their own comprehension making strategies (Gerston et al, 2001; NRP, 2001; Presley, 2002). For example, the use of prediction strategy can become the means by which students decide they read a particular text; they put to test their own predictions by re-reading the same text for more evidences in support or against their predictions.

3.i (b) Poor comprehenders are strategic at a lower level. They operate at a lower level of reading accuracy. They deal with the text at word level and fall short of monitoring their 
comprehension. They are weak at making association of their prior knowledge with the information that they encounter in the text and cannot "fill in the missing details." (Cain and Oakhill,1999). Poor comprehenders are poor at integrating information provided in the text for establishing cohesion between different sentences. Oakhill (1982) concludes that it would be difficult for a poor comprehender to draw the inference that "The mouse ate some bread" from the text, "The mouse ate some food. The food was bread. The mouse looked for cheese;" because strategically they would perform at a lower level. In fact, the wide range of differences between poor and good comprehenders has been summarized by Perfetti et al (p.143) in 'Sources of Comprehension Failure'. They provide evidence that "measure of working memory capacity separate better from lesser comprehenders." Yuill \& Oakhill, 1991, observe, "less skilled comprehenders show poorer inference making than do more skilled comprehenders". Numerous other studies like Mckeon et al (1983) showed that "children who learned relevant vocabulary understood the passages containing the key vocabulary."

3.i.(c) Good comprehenders can "detect" inconsistencies in a text and these "detectors" are better readers who show greater comprehension monitoring skill and use varied strategies to detect inconsistencies but "non-detectors" are either low ability or poor readers ( Perfetti, Marron \&Foltz, 1996).

3.i.(d) Inferential processing remained a strong predictor of reading comprehension level (Cane and Oakhill, 1999). Perfetti et al write, "Skilled comprehenders have inferentially representations. Less skilled comprehenders are poor inference makers. Thus, they create weak situation models and show incomplete comprehension of a passage (p.145)." 3.i.(e) Word reading skills become automatic with good comprehenders but it is 'context-dependent' and 'resourcedemanding' process in poor comprehenders.

3.i(f) Good domain knowledge makes good comprehenders, lack of this makes readers poor comprehenders. Perfetti et al refer to the studies like Anderson et at., 1978; Cheisi, Spilich, \&Voss, 1979; Spilich et al., 1979 and write,

"There have been ample demonstration that a domain is associated with text comprehension in that domain..........The other important thing about knowledge is that lack of it is a marker of poor comprehension (p.146-147)."

But does domain knowledge dictate inference making and comprehension monitoring? Perhaps. There are other factors which one may read to consider. Perfetti et al., 1996, prescribe:

"The reader's goals, including especially a willingness to expand effort a 'deep' comprehension are critical. This is why both inferences and comprehension monitoring are unlikely to be routine parts of reading. Only when a reader has both adequate knowledge and sufficient motivation will inferences be drawn and comprehension monitored in any useful sense (p.159)."

\section{4.i. How to enable children to improve their comprehension of texts}

To cite from Dowhower, S.L. (1999), a second grader, Colin (pseudonym), proudly announced that he has been using many of the ideas from the comprehension bulletin board to increase his understanding of books:

"I've been guessing ahead, making pictures in my head, and deciding what I am going to read for, before I start a book," he said, "These really helped me to think harder about the book and figure out what the author was trying to say when I am reading by myself 9p.672)." 
The teacher Mrs. E. complimented Colin for being so "strategic". The class had had strategy lessons and discussions as predictions, visual imagery, and a purpose setting throughout a set period of time 2and the children found many books that worked with these strategies. Clearly Wood \& Enders (2005) IEPC (Imagine, elaborate, predict and confirm) theory motivating students' interest is a key strategy to improve reading comprehension. This formula is also held credible through earlier studies carried by Duke \& Pearson, 2003; Wood \& Enders, 2005. Referring to these studies Gary Wolley (2005) writes:

"Children with reading comprehension difficulties do not always relate prior knowledge to text content, however, by encouraging students 10to elaborate and extend their verbalisation through questioning and summarising during the reading sessions their thinking process can be improved (p.40)."

So, teachers' role in training children to be able to think using all the higher skills of inferencing, questioning, retelling etc. is crucial (Kintsch, 2005).

\section{4. i. (a). Inference making training}

Teachers can train children to ask questions that demand them to make inferences and apply information to new situations. Kintsch (2005) found that such questions can help the reader form their own mental picture of events/information presented in the text.

\section{4. i.(b) Visual imagery training}

Researchers like Center et al., 1999; Duke \& Pearson, 2003; believe that many children do not normally use visual representation of text information while reading. They would improve reading comprehension if they receive visual imagery training. Teachers' can use IEPC technique to teach them to create imagined mental pictures of the text content. Garry Woolley (2005) reinforces this idea when he writes:

"Tutors can enable readers to more effectively tap into background knowledge while processing read text by visualizing and using summarizing strategies. These strategies can enhance children's mental models by having them discuss their imagined representations. When children re-shown how to use visual imagery they begin to rely more on their own prior knowledge and they become more motivated and affectively engaged (p.5)."

\section{4. i.(c) Comprehension monitoring training}

Poor comprehenders' initial failure in reading comprehension is that they operate at world level and falls short monitoring their comprehension. They fail make use of their prior knowledge and can't comprehend the text they are supposed to read. Alfassi (2004) reports that an intervention program supporting the ability of students with reading difficulties in using their relevant existing knowledge in reading a text improved their comprehension and extract the required information. Center, Freeman, Robertson and Outhred (1999) found that teaching pupils to construct mental images while they are reading increases their skills of inference and prediction which help them retain information from the text. These finding have been backed by many other studies including those of Sadoski, Goetz \& Rodriguez, 2000; and Wood \& Enders, 2005. Again, teachers' role in modeling these reading processes is crucial.

\section{4. i.(d) Improving technique of retaining word meaning}

Word becomes meaningful in 'real world' context. "Knowledge of word and context is critical in building a representation of a text for all readers (Perfetti et al., 1996, p.160)." But unfortunately, children with reading difficulties 
have a lesser store of vocabulary and this always jeopardize the purpose of reading. So, retaining word meaning through strategic training, e.g., picture cues, reference to familiar contexts, riddles, real world scenario etc. have proved to be successful in improving vocabulary and retaining word meaning. Gersten et al., 2001 refer to quite a few studies ( Bos \& Anders, 1990: Baumann \& Kameenui, 1991; Stanovich, 1986; Cunningham \& Stanovich, 1998) and write,

"The relationship between reading comprehension and vocabulary knowledge is strong and unequivocal and although the precise causal nature of the relationship is not completely understood, it does seem to be largely reciprocal. In other words, 65vocabulary knowledge contributes to reading comprehension and grows through reading experiences (p.283)."

\section{4. i.(e) Improving domain knowledge}

Knowledge of specialized subjects is crucial for readers to make sense of what they read. Role play, studying a selected author or artist, visits to library, museum, art gallery and continuous adult intervention, supervised reading, most of all, a rigorous routine of reading regularly have proved to be effective in improving domain knowledge.

\section{4. i.(f) Enhancing motivation}

Tunmer, Chapman, Greaney, \& Prochnow (2002) found that poor comprehenders' generally have no positive academic experience prior to their diagnosis of having comprehension problems. Consequently, as Gary Woolley (2005) found, they have "poor self-concept, poor self-esteem and poor academic achievement". It may be noted that children with poor comprehension skills, as Guthri \& Davies, (2003) observes, often become disengaged from literacy. This disengagement results in lack of motivation, lack of social interaction and lack of cognitive competence. So, collaboration among learners and a little positive interaction with the teachers have been suggested for ensuring better motivation and active engagement. Many reading and motivational theorists including Guthrie \& Davies, 2003; Pressley, 2002; Wigfield et al. 2004; are unanimous that poor comprehenders would perform better with opportunities to work collaboratively with others in pairs and in groups._Individually tasks should not be sacrificed in order to build confidence and self-respect.

\section{4. i.(g) Reciprocal teaching}

Palincar, (1986) in an intervention program involving a group of poor comprehenders observed that four strategies, such as, clarifying, summarizing, questioning, and predicting increase students' engagement and develop skills of comprehension in reading text. Zimmerman, 2002, findings proved that cognitive competence can be improved through "self-awareness, selfmotivation and knowing when and how to implement knowledge appropriately.”

\section{4. i.(h) Creativity and higher level of thinking training}

Zhang and Stenberg (2005) study claims that higher levels of motivation are related to higher levels of complexity. Hence, intervention programs can extend readers' motivation by using and creating and higher level of thinking. Guthrie,2003, suggest that a set aims of reading to learn and sharing learned information with others have proved effective for poor readers in increasing their engagement, application of learned strategies and comprehension. This kind of goal to share information in a personal but creative way enhances children's motivation to read and comprehend. For example, children can choose to present this information using individually made props, pictures or, even a multimedia presentation. 


\section{5. i. Issues facing teaching children read and comprehend in an additional language}

Learners of EAL can be misunderstood and undermined in terms of their ability in L2 use and comprehension as well as in L1. For practical reasons children from minority "speech communities" have been stigmatized as "LEP" (LimitedEnglish Proficient), or "low ability groups" (Jeff MacSwan, 2000, p.3). Crowl \& MacGinite (1974) report that even teachers with experience allocated unacceptably higher grades for the white students of America than their peers from African backgrounds for the same answers spoken. Their explanation was that this was the results were the reflection of a "vocal stereotype" meaning learners of a English from different linguistic backgrounds do have strong possibility of being wrongly assessed as poor comprehenders despite their operational skills at per with their white peers. MacSwan, (2000), posits,

"Such ability labels have widely used to stigmatize African American English (or Ebonics) as 'improper' or 'grammatically incorrect'."'

One can also be apprehensive that children from the linguistic minorities may underachieve and be deemed to be "poor comprehenders" because, as Cummins (1976) is quoted in MacSwan (2000),".....many bilingual children in subtractive bilingual learning situations may not develop native-like competence in either of their two languages. "Appropriate measures should be ensured so that EAL children are assessed in time and effective intervention programs should be in place to meet the needs of these children in teaching comprehension.

\section{6. (i) Recommendations}

The discussions in this article would instigate ideas as to how one would cope with the puzzling dilemma and the varied dimensions of children's reading comprehension skills. Issues about how good comprehenders tackle texts better than poor comprehnders and why call for many facets of reading disabilities including are dyslexia, hyperlexia and garden variety reading disability. Most of these issues have to be taken into consideration in facilitating lessons for reading comprehension. Other issues of learner motivation, teacher motivation, teaching strategies, teacher training, learner training, teaching-learning materials, teaching reading to learners as an additional language, bilingual learners, learning environment, learners' socio-cultural backgrounds and so on and so forth have to be considered while planning lessons on reading comprehension. Hence, teachers teaching language skills, particularly of reading comprehension, face the problems of selection from an abundance of methods and strategies designed by many teacher-educators and materials published professionally by established organizations over many years. It's a huge area of investigation and there are many scopes to study on all those problems and issues discussed above. The beauty of the tasks is that one is free to decide as to how they would approach their teaching reading. To sum up, it wouldn't be out of place to quote Patricia Babbitt (2002) who writes:

"Remember the adventures that lived and breathed between the pages of a really good book when, as a young reader, you slipped away undiscovered into your own magical world? My favorite works were Charlotte's Web, Arabian Nights, Huckleberry Finn, Arthurian Legends, and, later, the timeless tragedy of William Shakespeare's Hamlet. It is no surprise that many of us who loved such adventures grew up 
to become today's English teachers and writers. The surprise comes when we discover how many of our own students struggling readers are.

But surprise need not lead to a permanent state of frustration. By scaffolding reading instruction with various strategies, you will improve the reading abilities of most students, and you will begin to hear struggling readers say things like 'I remember every part of that story!' The key is to apply reading strategies persistently and imaginatively. Speaking of imagination let me ask you to indulge for a moment in a bit of guided imagery. Picture a beautiful, majestic cathedral soaring upward. Then visualize restoration experts at work on that architectural wonder, identifying the problems that need correcting and building a scaffold next to the structure so that they can interact with it at different heights. In a similar way, English teachers build a scaffold for struggling readers so that they can interact safely and securely with the text (p.1)."

Patricia's findings including two important ideas; one, "scaffolding reading instruction with various strategies" and two, "apply reading strategies persistently and imaginatively" can be considered as two most important recommendations to address the main research questions in the present study but a list of frequently used effective strategies, to refer to Patricia Babbit (2002) referring to the National Institute of Child Health and Human Development (NICHD, 1997), are mentioned below for possible recommendations to tackle any relevant problems regarding reading comprehension:

- Cooperative learning through pair work, group work and mixed ability group work, peer-teaching, peerchecking etc,;

- Comprehension monitoring through a three-phase activity with Pre-reading, Reading and Post-reading;
- Graphic organizers and story structure through Hierarchy Diagram, Story Matrix, Comparison/ Contrast;

- Question answering using, WH-questions (why, how, what, where, when etc.) in order to engage learners in their reading process effectively;

- Question generating through guiding students write questions about the story as a post-reading exercise and for formal tests or informal questioning games;

- Summarization, through bullet-points, travelogues, main points, interesting and non-interesting episodes, point-of-view presentation, journals, and letters;

- Multiple Strategy through the use of different media, such as texts both oral and written, 'realia' (pictures and artifacts), audio-visual materials, specific worksheets for story-line, content words for comprehension , and all these through differentiated activities using, pairs, groups and mixed ability groupings.

- A whole host of teaching methods /strategies used by modern ESOL/EFL practitioners, such as, Role-play, Songs and music, TPR (Total Physical Response), The Silent Way, Suggestopoedia, Dogme etc. can also be effectively used to address the dilemma and issues relating to improving reading comprehension.

\section{7. (i) Conclusion}

No single instructional method or resource can be effective for all children with reading comprehension difficulties. Majority of the teachers and linguists prefer the teachers to cater for the individual differences and address individual needs of the learners to facilitate learning environments that successfully 
engage all readers with equal opportunities to learn. The quality of children's reading comprehension is very much dependent up on the extent of their engagement with the tasks of reading. It is suggested that using graphic organizers and teaching learners how to construct mental images while they are reading improves their skills of inference, predictions and comprehension. Graphic organizers can be used to appeal to the individual learning styles and to develop higher level of creative thinking. It has been widely accepted that learner's reading comprehension for expository texts generally improves if they are trained to visualize through questions and summarizing during their reading sessions. So, teaching comprehension skills enables poor comprehenders to comprehend better and good comprehenders to excel in the business of comprehension.

\section{References}

Alfasssi, M. (2004): "Reading to learn: Effects of combined strategy instruction on high school students." The Journal of Educational Research, 97 (4), 171-184.

Anderson, R. C., \& Pearson, P.D. (1984): “A Schema-theoretic view of basic processes in reading comprehension.” In P.D. Pearson, R. Barr, M.L. Kamil and P. Mosental (Eds.) Handbook of reading research, White Plains, NY: Longman.

Babbitt, P. (2002): "Scaffolding: Strategies for Improving Reading Comprehension Skills." Prentice Hall eTeach. Retrieved from http://www.phschool.com/eteach/language arts/2002_12/essay. html

Baumann, J.F. and Kameenui, E.J. (1991). "Research on vocabulary instruction: Ode To Voltaire”, in J. Flood, J.J. Lapp, and J.R. Squire (Eds.), Handbook of research on teaching the English language arts (pp. 604-632). New York: MacMillan.

Block, C.C. (2004): Teaching comprehension: The comprehension process approach. Boston: Pearson.
Bos C.S., \& Anders, P.L. (1990): "Effects of interactive vocabulary instructions on the students.” Learning Disability Quarterly, 13, 3142.

Cain, K. (2006). "Children's reading comprehension: The role of working memory in normal and impaired development." Working memory and education, 3, 61-91.

Cain K., \& Oakhill J.V. (1999): "Inference making ability and its relation to comprehension failure in young children." Reading and writing: An interdisciplinary journal, 11 489-503.

Cain, K., Oakhill, J., \& Bryant, P. (2004). “Children's reading comprehension ability: Concurrent prediction by working memory, verbal ability, and component skills.” Journal of Educational Psychology, 96, 31-42.

Carpenter, P.A. \& Just, M.A. (1988): "The role of working memory in language comprehension.” In D. Klahr \& K. Kotovsky (Eds.), Complex information processing: The Impact of Herbert A. Simon (pp-31-68). Hilisdale, NJ: Lawrence Eribaum Associates.

Center, Y., Freeman, L., Robertson, G. \& Outhred, L. (1999): “The effect of visual imagery training on the reading and listening comprehension of low listening comprehenders in Year 2.” Journal of Research in Reading, 22(3), 241-256.

Chiesi, H.L., Spilich, G.J. \& Voss, J.F. (1979): “Acquisition in domain-related information I relation to high and low domain knowledge." Journal of Verbal Learning and Verbal Behaviour. 18, 257-274.

Crowl,T. \& MacGinitie,W., (1974): "The Influence of Students' Speech Characteristics on Teachers' Evaluation of Oral Answers.” Journal of Educational Psychology, 66(3). 304-308.

Cummins, J. (1976): “The Influence of Bilingualism on Cognitive Growth: A Synthesis of Research Findings and Explanatory Hypothesis.” Working papers on Bilingualism, 9, 1-43. 
Derksen, B. (2012): "What's the Difference?" Retrieved from https://openaccess.leidenuniv.nl/bitstream/handle/1887/19493/Thesis ReadingComprehension

Dowhower, S.L. (1999): "Supporting a strategic stance in the classroom: A comprehension framework for helping teachers help students to be strategic.” The Reading Teacher, Vol.52, No.7.

Duke, N.K. and Pearson, P.D. (2002): "Effective practice for developing reading comprehension", in A.E. Farstrup and S.J. Samuels (Eds.), What research has to say about reading instruction, $3^{\text {rd }}$ ed., (pp.205-242). Newark, DE: International Reading Association.

Fountas, Irene C. (2001). Guiding readers and writers, grades 3-6: Teaching Comprehension, Genre, and Content Literacy, Heinemann Educational Books.

Gersten, R., Fuchs, L.S., Williams, J.P. \& Baker, S. (2001): "Teaching Reading comprehension strategies to students with learning disabilities: A review of research.” Review of Educational Research, 71, 279-320.

Gough,P.B. \& Tunmer, W.E. (1986). "Decoding, reading, and reading disability.” Remedial and Special Education,7.

Graesser, A. C., Swamer, S. S., Baggett, W. B., \& Sell. (1996). "New models of deep comprehension.” In B. K. Britton and A. C. Graesser (Eds.), Models of understanding text (pp. 1-33), New Jersey: Lawrence Erlbaum.

Guthrie, J.T., \& Davis, M.H. (2003): "Motivating the struggling readers in middle school through an engagement model of classroom practice.” Reading and Writing Quarterly, 19, 59-85.

International Reading Association. 1996 Summary of the (U.S.) National Reading Panel Report "Teaching Children to Read." Retrieved from http://www.reading.org/advocacy/nrp/index.html
Jhingran, D. (2011): "Reading Failure in Early Primary Grades: A Serious Challenge to Equity in Primary Education". Retrieved from http://www.create-rpe.org/pdf_documents/Delhi2011D.Jhingran.pdf

Johnson-Laird, P. N. (1983). Mental Models: Towards a Cognitive Science of Language, Inference, and Consciousness. Cambridge, MA: Harvard University Press.

Kate Nation and Philip Angell (2006): Learning to read and learning to Comprehend." London Review of Education, Vol. 4, No. 1, March 2006, 77-87.

Kintsch, E. (2005): "Comprehension theory as a guide for the design of thoughtful questions." Topics in Language Disorders, 25(1), 5164.

Kintsche, W. and Van Dijk, T.A. (1978): "Towards a Model of Text Comprehension and Production.” Psychological Review, 95, 163182.

Manset-Williamson, G. \& Nelson, J. M. (2005) "Balanced, strategic reading instruction for upper elementary and middle school students with reading disabilities: A comparative study of two approaches." Learning Disability Quarterly, 28, 59-74

MacSwan, J. (2000): "The Threshold Hypothesis, Semilingualism, and Other Contributions to a Deficit View of Linguistic Minorities." Hispanic Journal of Behavioral Sciences, Vol.1, 3-45.

Mckeown, M.G., Beck, I.L., Omanson, R. \& Perfetti, C.A. (1983):

"The effects of long term vocabulary instruction on reading comprehension : A replication.” Journal of Reading Behaviour, 15, $3-18$.

Nation, K., Clarke, P., Snowling, M. J. (2002). "General cognitive ability in children with reading comprehension difficulties.” British Journal of Educational Psychology, 72, 549-560.

National Reading Panel. (2001): Teaching students to read: Report of the comprehension instruction sub-group to the National Institute of Child Health and Development. Washington D.C.: NICD. 
Oakhill, J.V., (1982): "Constructive Processes in Skilled and Unskilled Comprehenders’ Memory for Sentences.” British Journal of Psychology, 73, 13-20.

Perfetti C.A., Marron, M.A. \& Foltz P. W. (1996): "Sources of Comprehension Failure: Theoretical Perspectives and Case Studies." In Reading Comprehension Difficulties: Processes and Intervention, Cesare Cornoldi \& Jane V. Oakhill (Eds.), Manhwa, NJ : Lawrence Erlbaum Assoc.

Pressley, M. (2002): "Comprehension instructions: What makes sense now, what might make sense soon.” International Reading Association Online Document. Retrieved from http://www.readingonline.org/articles/ handbook/pressley/

Sadoski, M., Goetz, E. T., \& Rodriguez, M. (2000). "Engaging texts: Effects of concreteness on comprehensibility, interest, and recall in four text types.” Journal of Educational Psychology, 92(1), 85-95.

Singer, M. (1994). "Discourse inference processes." In M. Gernsbacher (Ed.), Handbook of Psycholinguistics. San Diego: Academic Press

Singer, M., \& Ferreira, F. (1983). "Inferring consequences in story comprehension." Journal of Verbal Learning and Verbal Behavior, 22, 437-448.

Snowling, Margaret, J. (2010): Reading Comprehension: Nature, Assessment and Teaching. York: Centre for Reading and Language.

Stothard, S. E., \& Hulme, C. (1995). “A comparison of phonological skills in children with reading comprehension difficulties and children with decoding difficulties.” Journal of Child Psychology and Psychiatry, 36, 399-408.

The National Literacy Strategy, (1988): The Searchlights Model of Text Reading: DfES, Department for Education and Science, UK.

Tunmer,W.E., Chapman, J.W., Greaney, K.T. and Prochnow, J.E. (2002). "The contribution of educational psychology to intervention research and practice." International Journal of Disability, Development and Education, 49(1), 11-29.

Vonk, W. Spilich, G.J., Vesonder, G.T., Chiesi H.L. \& Voss, J.F. (1979): "Text processing of domain-related information for individuals with high and low domain knowledge." Journal of Verbal Learning and Verbal Behaviour, 18, 275-290.

Wigfield, A., Guthrie, J.T., Tonks, S. and Perencevich, K.C. (2004): "Children's motivation for reading: Domain specific and instructional influences." The Journal of Educational Research, 97 (6), 299-309.

Wood, K.D., \& Enders, C. (2005): “Motivating Students' interest with the imagine, elaborate, predict and confirm (IEPC) strategy." The Reading Teacher, 58(4), 346-357.

Woolley, G. (2005): The Influence of Learning Styles on the Motivation and Engagement of Students with Reading Comprehension Difficulties. Canberra: University of Canberra.

Yuill, N. \& Oakhill, J. (1988): "Effects on inference awareness training of poor reading comprehension.” Applied Cognitive Psychology, 2, 33-45.

Yuill, N. \& Oakhill, J. (2010): Children's Problems in Text Comprehension: An Experimental Investigation. Cambridge: Cambridge University Press.

Yuill,N. ,Oakhill, J., \& Parkin A. (1989): "Working memory, comprehension ability and the resolution of text anomaly." British Journal of Psychology, 80, 351-361.

Zhang, L. and Sterrnberg, R.J. (2005): "A Threefold Model of Intellectual Styles.” Educational Psychology Review, 17(1), 1-53.

Zimmerman, B. (2002): "Becoming a Self-regulated Learner: An overview”, Theory into Practice, Volume 41, Number 2, Spring 2002, College of Education, The Ohio State University, pp. 54-70. 